\title{
Contributing to the ICNP®: validating the term cultural diversity
}

\author{
N Geyer, M Cur \\ Democratic Nursing Organisation of South Africa
}

MD Peu, M Cur

University of Pretoria

S Roussouw, B Cur (Hons)

University of Pretoria

J Morudi, B Cur

Weskoppies Hospital

E Uys, B Cur

Project Coordinator, Democratic Nursing Organisation of South Africa

Keywords:

ICNP®; cultural diversity; validate terms

\section{Abstract: Curationis 28(2): 61-69}

Aim

The specific aims of this study were to:

- $\quad$ Propose a definition of the term cultural diversity;

- Validate the term cultural diversity; and

- Submit a term and definition for international utilisation to the International Council of Nurses (ICN) for consideration for inclusion in the ICNP®.

\section{Background}

South Africa was one of four African countries (Botswana, South Africa. Swaziland, and Zimbabwe) funded by the WK Kellogg Foundation to participate in the ICNP® project. South Africa had 2 research groups. One of the research groups identified the term cultural diversity to define.

\section{Method}

This was a qualitative study where a philosophical perspective was used to explore, explain and describe nursing practice. The combined method proposed by the International Council of Nurses (ICN) was utilised to define and validate the term cultural diversity.

\section{Findings}

Validation and literature review provided sufficient support for the defined characteristics and the term was finally defined and submitted to ICN in November 2002 as: CULTURAL DIVERSITY is a type of CULTURE with the specific characteristics: co-existence of different groups, e.g. ethnic, religious, linguistic and other groups each with their own values and belief systems, traditions and different lifestyles.

\section{Conclusion}

The research group was informed in December 2003 of the ICNP® Evaluation Committee recommendation that the term cultural diversity will be included in the ICNP®. 


\section{Background}

The International Classification of Nursing Practice (ICNP®) is a classification of nursing phenomena, actions and outcomes. The ICNP® provides a terminology for nursing practice that serves as a unifying framework into which existing nursing vocabularies and classifications can be cross-mapped to enable comparison of nursing data (ICN 200 la).

South Africa was one of four African countries (Botswana, South Africa, Swaziland, and Zimbabwe) funded by the WK Kellogg Foundation to participate in the ICNP® project, which started in 1999 and was concluded in March 2003. There was a parallel WK Kellogg Foundation project in four Latin American countries (Brazil, Chile, Colombia, and Mexico). The purpose of the South African project was to identify and define terms used by nurses in primary health care services. The project consisted of two research groups from two different provinces in South Africa, namely Gauteng and Eastern Cape. The purpose for selecting research groups in these two provinces was that one represents an urbanized community and the other a more rural community. Although these communities will have some of the same needs, there are differences in their needs profiles and the terms identified by the two groups have proven these differences (Geyer \& Uys 2001).

The challenge to identify terms relevant to the South African situation and to develop a term that is relevant to the global community made for some interesting discussion and learning opportunities. One of the terms developed by the Gauteng Research group was informal settlement.

\section{Purpose}

The overall purpose of participating in the development of the ICNP® was to establish common terminology for describing nirsing practice. A common terminology improves communication among nurses and other members of the multidisciplinary team, as well as provides standardized clinical data for describing and analysing nursing practice. The specific aims of this study were to propose a definition of the term cultural diversity; to validate the term cultural diversity and to submit a term and definition for international utilisation to the International Council of Nurses (ICN) for consideration for inclusion in the ICNP®.

\section{Research design}

This was a qualitative study where a philosophical perspective was used to explore, explain and describe nursing practice (Polit, Beck \& Hungler 2001). The research group members developed a definition to describe "cultural diversity". The definition was then validated amongst relevant stakeholders by determining the extent of agreement with the proposed definition.

A combination of the methods proposed by the ICN was used for developing terms in the South African project (ICN 200lb). The procedure followed consisted of a number of steps followed by the research group participants.

The research group selected a term, by prioritising terms listed by the participants. Using a score of 1-5 (1 being the lowest and 5 being the highest priority), all terms were scored by the research group members to determine the order in which the terms were developed. The characteristics of the selected term were then developed in a similar way. The list was carefully checked to ensure that the characteristics were true characteristics and not causes or consequences. The research group. scored the characteristics and only those with a score higher than 4 were included for the definition. A preliminary definition of the selected term was developed. A validation form was prepared explaining the process and providing the term and its characteristics for the opinion of other experts in the clinical field.

Before submitting the validation form to a wider stakeholder group, the form was piloted among nurses who are not part of the research group. Where required, amendments were made to ensure clarity of the expectations of the research group. Other nurses involved in primary health care and community members exposed to informal settlements were requested to complete the validation form.

The completed validation forms were returned to the research group where the data were analysed. A literature survey was performed to determine the support for the survey findings of the characteristics of the term. Based on the literature review and survey findings, the definition was finalized, the process summarized in the prescribed format and submitted to the ICNP® Evaluation Committee.

\section{Subjects and sampling}

The Gauteng Research Group consisted of nine nurses with a primary health care background. These participants volunteered for the project and complied with the predetermined criteria for participation. The criteria that the nurses complied with were a current position in primary health care (PHC), experience of at least two years in a PHC field and availability to participate in the research group activities. All persons, who indicated their interest to participate, were invited to become part of the research group. The activities of the research group were co-ordinated and recorded by a project co-ordinator and facilitated by a staff member of the Democratic Nursing Organisation of South Africa (DENOSA).

The sample for the validation study consisted of nurse practitioners and community members. Convenience sampling was used for the validation of the term and its characteristics (Polit, Beck \& Hungler 2001). The validation forms were distributed by research group members within a prescribed time frame amongst nurse practitioners and community members in the Gauteng, North West and the Eastern Cape provinces in South Africa. These were the areas where the research group participants had access and therefore the ability to ensure that the prescribed processes was adhered to and that persons who could not understand, read or write could be assisted.

\section{Data collection}

The research group participants, the research project co-ordinator and the project facilitator conducted all the data collection during the different phases of the study. This included distribution and collection of the validation survey forms.

\section{Ethical considerations}

All research group participants had permission from their employers to participate in the project. For the validation process permission was obtained from employers to have access to staff members involved in service delivery. Each individual person who completed a validation form was informed of the process and the reason for the study. They were advised that 


\begin{tabular}{|ll|l|}
\hline Characteristic & Remark \\
\hline 1 & Different Lifestyle & Characteristic \\
\hline 2 & Based on different customs & Characteristics \\
\hline 8 & Based on different tradition & Characteristic \\
\hline 9 & Mixed belief systems & Characteristic \\
\hline 10 & Mixed values & Characteristic (combine with belief systems 9) \\
\hline 11 & Norms & Characteristic \\
\hline 12 & Standards & Characteristic (combine with norms 11) \\
\hline 18 & Various learned behaviour & Characteristic \\
\hline 28 & Communication style & Characteristic \\
\hline 31 & Different ethnic groups & Characteristic \\
\hline
\end{tabular}

participation was voluntary and anonymous. Persons who did not wish to participate were not discriminated against (DENOSA 1998).

\section{Defining the term cultural diversity}

The process of defining the term cultural diversity was performed in different phases. Each phase is described below.

\section{Selecting the term "cultural diversity"}

The term, originally identified as "multi cultural" was identified by the research team in November 2000. "Multi cultural" was initially listed together with 15 other terms as primary health care phenomena important to nursing practice. To prioritise terms for the project, all terms were rated using a score of 1-5 ( 1 being the lowest and 5 being the highest priority). According to the scores the terms of preference, considered to be the most common phenomena in PHC practice, were Home-based care (4.75); Multi Cultural (4.5); Community based organizations (4.5); Traditional Healers (4.37); Teenage pregnancy (4.37); Rehabilitation (4.12) and Health Forum (4).

The subsequent research group activities involved development of the three terms with the highest scores, which included multi cultural. In considering the literature available on "multi cultural" the research group debated and agreed to change the term to "cultural diversity".

\section{Developing the initial definition}

The research team developed the main characteristics of cultural diversity in July 2001. In selecting the characteristics, each research group member was given an opportunity to list characteristics that describe the term. Thirtyone (31) characteristics were identified. After group discussion on each characteristic, 21 were excluded and 10 were Table 2: Initial characteristics of cultural diversity

\begin{tabular}{|l|l|}
\hline Characteristic & Mean score \\
\hline Different lifestyle & 4.9 \\
\hline Based on different customs & 4.7 \\
\hline Based on different tradition & 5 \\
\hline Mixture of belief systems and values & 4.8 \\
\hline Mixture of norms and standards & 4.1 \\
\hline Various learned behaviour & 3.4 \\
\hline Use of different communication styles & 3.3 \\
\hline Co-existence of ethnic groups & 4.8 \\
\hline
\end{tabular}
retained as characteristics of cultural diversity. The research group consulted dictionaries and text books to clarify the remainder of the identified characteristics and it was agreed that mixed values should be combined with belief systems and standards should be combined with norms (Table 1).

The research group rated each of the 8 characteristics using the same scale of 1 5. All the characteristics that obtained a mean score of four or more were included in the definition. Six characteristics of cultural diversity had a mean score $>4$ (Table 2).

\section{Developing the validation form}

The research team developed a draft validation form. An option of "other" was added to the list of 8 characteristics for the respondents to add other characteristics that may have been left out by the research group. The form also made provision for persons to indicate who they were.

\section{Pilot testing of the validation form}

A pilot test was conducted with the validation form in order to check whether participants understood and agreed with the content. For the pilot test each of the research group members distributed the validation form to two experts in the field who would not participate in the final data collection process. Pilot testing was conducted during August 2001 and all feedback about the forms was submitted to the project co-ordinator in September 2001.

Feedback from the pilot test did not identify any areas that had to be addressed by the research group before 


\begin{tabular}{|l|l|l|l|}
\hline Profile of respondents & No & Environment where obtained & No \\
\hline Nurse practitioners & 40 & Educational institutes & 6 \\
\hline Unspecified & 4 & Health Departments & 8 \\
\hline Priest & 1 & Clinics and hospitals & 24 \\
\hline & & Private sector & 2 \\
\hline & & Church & 1 \\
\hline & & Unspecified & 4 \\
\hline
\end{tabular}

members of the Eastern Cape research group were also requested to complete a validation form. The research group members conducted interviews and completed the validation forms, or ensured self-administration of the form by the respondents. The ICN Consultant and neighboring African countries involved in the ICNP® in-country projects were also consulted for their views on the term cultural diversity.

\section{Data analysis of validation forms}

The final data analysis was conducted in

the validation process could commence. Validation commenced in September and was completed in November 2001. See annexure 1 for informal settlement validation form.

\section{The initial definition}

The identified characteristics were used to develop the initial definition, which was used for the validation form. To develop this definition the research group had to decide where the term would fit into the current ICNP® structure. The initial definition was the following:

Cultural diversity is a type of CULTURE with the specific characteristics: co- existence of ethnic groups based on different customs and traditions and a mixture of belief systems and values, norms and standards and different life styles.

\section{Validation of the term cultural diversity}

Each member of the research group received 5 validation forms and conducted the data collection for the term validation between September and November 2001. One of the research group participants was out of the country at this stage with the result that 40 forms were circulated for validation. The ten
November 2001 at a scheduled meeting of the research group. From the 50 distributed forms 47 were returned, indicating a $94 \%$ response rate. Two of the forms were not used due to the fact that 2 persons had completed two forms instead of only 1 . The respondents on the forms that were received consisted of 40 nurse practitioners (6 from educational institutions; 8 from health departments; 24 from clinics and hospitals and 2 from private sector); 1 priest and 4 were unspecified. The breakdown of the respondents is listed in table 3 .

Each validation form was numbered on

Table 4 Results obtained from the validation forms

\begin{tabular}{|c|c|c|c|}
\hline CHARACTERISTIC & YES & NO & REMARKS \\
\hline Co-existence of ethnic groups & $\begin{array}{l}40 \\
88.89 \%\end{array}$ & 5 & $\begin{array}{l}\text { - } \quad \text { This is not synonymous with cultural diversity (1) } \\
\text { - } \\
\text { - } \\
\text { - } \\
\text { - }\end{array}$ \\
\hline Based on different customs & $\begin{array}{l}41 \\
91.11 \%\end{array}$ & 4 & $\begin{array}{l}\text { - } \quad \text { Customs are linked to culture (1) } \\
\text { - } \quad \text { Same as characteristics } 4 \text { \& } 5 \text { (1) }\end{array}$ \\
\hline Based on different tradition & $\begin{array}{l}43 \\
95.56 \%\end{array}$ & 2 & $\begin{array}{l}\text { - } \quad \text { Same as characteristics } 4 \text { \& } 5 \text { (1) } \\
\text { - } \quad \text { Tradition is linked to culture (1) }\end{array}$ \\
\hline $\begin{array}{l}\text { Mixture of belief systems and } \\
\text { values }\end{array}$ & $\begin{array}{l}38 \\
84.44 \%\end{array}$ & 7 & $\begin{array}{l}\text { Dependant on different upbringing ( } 1 \text { ) } \\
\text { Disagree because religion and culture are two } \\
\text { separate things (1) }\end{array}$ \\
\hline Different lifestyles & $\begin{array}{l}38 \\
84.44 \%\end{array}$ & 7 & $\begin{array}{l}\text { Disagree because lifestyle is not necessarily linked to } \\
\text { culture (2) } \\
\text { Disagree because lifestyle can be more related to } \\
\text { econmics than to culture (1) }\end{array}$ \\
\hline
\end{tabular}


receipt for easy reference during the discussions that follow the validation process. The content of the validation forms was transferred to an Excel spreadsheet to calculate percentage of agreement on characteristics. Comments received were included in an additional spreadsheet column.

It can be concluded from the results that all six (6) characteristics provide clarity on what cultural diversity is and the respondents supported the definition developed by the researchers. Seven respondents reiterated the importance of understanding, respecting and tolerating different cultures for a harmonious and peaceful country. Five members mentioned integrating other values and norms; copying other cultures; forming a new culture; benefit from other cultures; ethnic groups also share some South African Culture. It was recommended that interdependency and Tolerance has to be included in the list of characteristics. All characteristics were adequately supported during the validation process as shown in table 4

\section{Literature overview}

The research group completed a review of the literature to verify the characteristics included in the definition of the term cultural diversity. All research group participants; the project coordinator and the facilitator were responsible for sourcing literature. The literature contained both local and international sources. The Research Group had a total of 23 articles that were submitted at the May 2002 meeting for consideration and evaluation to finalize the term and definition. Literature were numbered as they were received and were therefore not in an alphabetical order at the time of the literature validation.

Table 5 provides an exposition of literature support for each of the characteristics; the top row consists of the reference articles as they are listed below the table and the $X$ shows the characteristics confirmed in the stated article.

\section{Discussion of the validation and literature study}

The literature study provided the following information that supported each of the characteristics of the term.
With regard to CO-EXISTENCE OF DIFFERENT ETHNIC GROUPS more than $50 \%$ of the literature referred to more than just ethnic groups. Two members of the group reasoned that the group should keep to ethnic groups but the rest agreed that cultural diversity included more than just ethnic diversity. On the majority vote it was decided to refer to other groups. The majority suggested that a few examples should be included. Suggested examples were ethnic, religious, linguistic and socio-economic groups but one member did not agree with the inclusion of socio-economic groups and to refrain from controversy it was decided to include only neutral groups but leave it open-ended by saying "and other groups"

The proposal to include different customs and traditions were considered. The majority supported that customs be omitted and only be described as different traditions.

It was agreed to omit norms and standards because it was already omitted in the validation and if the term was placed as part of the family of norms and attitudes it was already included.

The potential positions for placement of the term "cultural diversity" in the Beta version that were eliminated included nursing phenomenon (not specific enough); health system (lacked the components necessary to classified under it); value belief (pertained to the individual) and community composition (disregarded). The majority supported the motion to classify it as a type of culture.

\section{Finalisation of the definition of cultural diversity}

In July 2002 the research group redefined the term cultural diversity based on the findings of the validation study and discussion in the South African context. The initial definition indicated that for placement in the ICNP® Beta 2 version, the research group initially thought cultural diversity could be a type of culture. After extensive discussion and literature review it was agreed that this remains a form of culture. The final definition was as follows:

CULTURAL DIVERSITY is a type of CULTURE with the specific characteristics: co-existence of different groups, e.g. ethnic, religious, linguistic and other groups each with their own values and belief systems, traditions and different lifestyles.

\section{Limitations of this study}

There are limitations to this study. Although neighbouring countries were consulted, data was only collected within the areas where the researchers were based (Gauteng, North - West and Eastern Cape Provinces) providing a selective view.

\section{Submission of the term to ICNP@}

The process of the development of the term cultural diversity was summarised on the prescribed form and submitted to ICN in November 2002. ICN distributes the term to experts in a related nursing practice area who volunteer to conduct further review. The ICNP® Evaluation Committee then evaluates the expert review and considers inclusion in the ICNP®.

\section{Inclusion of the term into the ICNP®}

The research group has successfully developed and validated the term cultural diversity. In December 2003 the ICNP® Evaluation Committee informed the research group participants that cultural diversity is one of 12 terms submitted by DENOSA that has been accepted for inclusion in the ICNP®. With this announcement the research group has managed to achieve all the aims of the project.

\section{Conclusion}

Defining the term "cultural diversity" was a challenging exercise, especially in view of the fact that the definition had to be applicable internationally. Acceptance of the defined term is therefore meaningful for nursing and midwifery practice as it contributes to a standardized vocabulary for nurses and nursing globally - all who refer to cultural diversity, will have the same understanding wherever the term cultural diversity (with its generic characteristics) is used irrespective of where the term is used.

Reflecting on the process followed in defining the term, there are a few lessons to be learnt. The process for validation of the term would have been enriched if more provinces in South Africa and other 
countries outside of Africa could have been used in the validation process.

Obtaining ethics approval for the project has proven to be problematic as all the research ethics committees in South Africa are linked to universities. These committees were of the opinion that they could not execute any control over the project once approved, as DENOSA was not linked to the relevant universities in any way. These institutions therefore were not available to evaluate and provide ethics approval for the project. The ethical guidelines available to DENOSA were used to assist with compliance with the ethical principles for the study. While the ethical guidelines did provide assistance, there is a need for DENOSA to develop an ethics committee to consider non-university related nursing projects for ethical approval in future.

\section{Acknowledgements}

We wish to thank all who contributed to the development of the term. Many people have shared their expertise on "cultural diversity". We particularly wish to thank W.K Kellogg Foundation, DENOSA and the ICN for making participation in this project possible. The research group members are thanked for their time, effort. expertise and sometimes disagreements and debates that made the final submission of the term possible. The other Research Group members are:

$\begin{array}{ll}\text { - } & \text { Zodwa Gumede } \\ \text { - } & \text { Emma Mabidilala } \\ \text { - } & \text { Gladys Sithole } \\ \text { - } & \text { Gugu Shongwe } \\ & \text { Salamina Mmuwe-Hlahane }\end{array}$

\section{List of Sources}

AMERICAN ACADEMY OF PEDIATRICS, 2000: Enhancing the racial and ethnic diversity of the pediatric workforce (RE9931). Pediatrics. 105(1): 129-131.

ANDREWS MM AND BOYLE, JS 1999: Transcultura' concepts in nursing care. Lippincott. Philadelphia.

BOUWER, M; DREYER, M; HERSELMAN, S \& HATTINGH, HS Contemporary trends in community nursing.

BOWMAN, BT 1994: Cultural diversity and academic achievement. Ncrel urban education program, Chicago. http:// www.ncrel.org/sdrs/areas/issues/ educatrs/leadrshp/le0bow.htm.

CARLOWE, J 1998: Orthodox care. No thanks for the memories. Nursing Times. December 2, 94(48): 32-33.

CHIPFAKACHA, V 1994: The role of culture in primary health care. SAMJ. 84 (12) December 1994; 860-862.

CLARK, MJ 1996: Nursing in the community. Second edition. Appleton \& Lange, Connecticut.

DENOSA 1998: DENOSA Position Statements: Ethical guidelines for nurse researchers. DENOSA. Pretoria.

\section{ETHNIC AFFAIRS COMMISSION OF}

NSW 2001: Ethnic affairs and cultural diversity. Sydney. http:// www.eeo.nsw.gov.au/jobs/eeointro/ diversity.htm

FERGUSON, SA 1994: Facilitating multicultural competence. Child Care Worker. 12 (7) July 1994: 3 \& 4.

GEYER, N \& UYS E 200: South AfricaICNP® Country Project. ICNP Bulletin. $1,2-4$.

GIGER. JN; DAVIDHIZAR, R 2002: Culturally competent care: Emphasis on understanding the people of Afghanistan, Afghanistan Americans, and Islamic culture and religion. International Council of Nurses. International Nursing Review. 49(2): 79-86.

HAYES, VL 1998: Appreciating Patient Diversity. AJN, 98 (11): 80.

INTERNATIONAL COUNCIL OF NURSES (ICN) 2001A: ICNPß Beta 2. ICN: Geneva, Switzerland.

INTERNATIONAL COUNCIL OF NURSES (ICN) 2001B: ICNP® Review Process: How to participate. ICN, Geneva, Switzerland.

IRVINE, JM 1994: Sexual cultures and the construction of adolescent identities. Temple University Press, Philadelphia.

JARVIS, D 1998: Transcultural nursing. Seeing things in black and white. Nursing Times. 94(42): $32 \& 33$.

JEZEWSKI, MA 1993: Culture brokering as a model for advocacy. Nursing \& Health Care. February 1993: 78-85.

LEE, B 1999: Tackling Racism. Nursing Standard. 12(28): 14-16.

LEININGER, M 1994: Transcultural nursing education: A worldwide imperative. Nursing \& Health Care .15(5): 254-257.

MCCAFFERY, M 1999: Pain Control. AJN, 99(8): 18.

MELIFONWU, R 1999: Supporting Act. Nursing Standard. 13(40): 18.

MENSAH, J 1999: The richest mix. Nursing Standard. 13(23): 70.

POLIT DF, BECK C T \& HUNGLER BP 2001: Essentials of nursing methods. appraisals and utilisation. $5^{\text {th }}$ Edition. Lippincott: New York.

ROSELLA, JD AND REGANKUBINSKI, MJ \& ALBRECHT, SA 1994: The need for multicultural diversity among health professionals. Nursing \& Health Care. 15,(5): 242-246.

SADLER, C 1999: Promoting diversity Nursing Standard. 13(39): 14-16.

SPRADLEY, BW \& ALLENDER, JA 1996: community health nursing concepts and practice. Fourth Edition. Lippincott, Philadelphia.

ENGBRETSON, J; LITTLETON, LY2001: Cultural negotiation: A constructivist - based model for nursing practice. Nursing Outlook. September/ October 2001: 223-230. 
Table 5 Exposition of the literature support for the characteristics

\begin{tabular}{|c|c|c|c|c|c|c|c|c|c|c|c|c|}
\hline Characteristics & $\begin{array}{l}\text { Ref } \\
1\end{array}$ & $\begin{array}{l}\text { Ref } \\
2\end{array}$ & $\begin{array}{l}\text { Ref } \\
3\end{array}$ & $\begin{array}{l}\text { Ref } \\
4\end{array}$ & $\begin{array}{l}\text { Ref } \\
5\end{array}$ & $\begin{array}{l}\text { Ref } \\
6\end{array}$ & $\begin{array}{l}\text { Ref } \\
7\end{array}$ & $\begin{array}{l}\text { Ref } \\
8\end{array}$ & $\begin{array}{l}\text { Ref } \\
9\end{array}$ & $\begin{array}{l}\text { Ref } \\
10\end{array}$ & $\begin{array}{l}\text { Ref } \\
11\end{array}$ & $\begin{array}{l}\text { Ref } \\
12\end{array}$ \\
\hline $\begin{array}{l}\text { Co-existence of ethnic } \\
\text { groups }\end{array}$ & $\mathrm{X}$ & $X$ & $X$ & $\mathrm{X}$ & & $\mathrm{X}$ & $X$ & $\mathrm{X}$ & $X$ & & $\mathrm{X}$ & $X$ \\
\hline $\begin{array}{l}\text { Based on different } \\
\text { customs }\end{array}$ & $\mathrm{X}$ & $\mathrm{x}$ & $\mathrm{x}$ & & $\mathrm{x}$ & & & & & $\mathrm{x}$ & & \\
\hline $\begin{array}{l}\text { Based on different } \\
\text { traditions }\end{array}$ & & $\mathrm{X}$ & & $\mathrm{X}$ & $\mathrm{X}$ & $\mathrm{x}$ & $\mathrm{X}$ & & $\mathrm{X}$ & $\mathrm{x}$ & & \\
\hline $\begin{array}{l}\text { Mixture of belief system } \\
\text { and values }\end{array}$ & $\mathrm{X}$ & $\mathrm{X}$ & $\mathrm{X}$ & $\mathrm{x}$ & $\mathrm{X}$ & $\mathrm{x}$ & $\mathrm{X}$ & & $\mathrm{X}$ & $\mathrm{x}$ & $\mathrm{X}$ & $X$ \\
\hline $\begin{array}{l}\text { Mixture of norms and } \\
\text { standards }\end{array}$ & $X$ & $\mathrm{X}$ & $\mathrm{X}$ & $\mathrm{X}$ & $\mathrm{X}$ & $x$ & $\mathrm{X}$ & & $X$ & $\mathrm{X}$ & $\mathrm{X}$ & $\mathrm{X}$ \\
\hline Different lifestyle & & $\mathrm{X}$ & $\mathrm{X}$ & $\mathrm{X}$ & $X$ & $\mathrm{X}$ & $\mathrm{x}$ & & $\mathrm{X}$ & $\mathrm{X}$ & $\mathrm{x}$ & $\mathrm{X}$ \\
\hline Characteristics & $\begin{array}{l}\text { Ref } \\
13\end{array}$ & $\begin{array}{l}\text { Ref } \\
14\end{array}$ & $\begin{array}{l}\text { Ref } \\
15\end{array}$ & $\begin{array}{l}\text { Ref } \\
16\end{array}$ & $\begin{array}{l}\text { Ref } \\
17\end{array}$ & $\begin{array}{l}\text { Ref } \\
18\end{array}$ & $\begin{array}{l}\text { Ref } \\
19\end{array}$ & $\begin{array}{l}\text { Ref } \\
20\end{array}$ & $\begin{array}{l}\text { Ref } \\
21\end{array}$ & $\begin{array}{l}\text { Ref } \\
22\end{array}$ & $\begin{array}{l}\text { Ref } \\
23\end{array}$ & Total \\
\hline $\begin{array}{l}\text { Co-existence of ethnic } \\
\text { groups }\end{array}$ & $\mathrm{X}$ & $\mathrm{X}$ & $\mathrm{X}$ & $\mathrm{X}$ & $\mathrm{X}$ & $\mathrm{X}$ & $\mathrm{X}$ & $\mathrm{X}$ & $\mathrm{X}$ & & $\mathrm{x}$ & 20 \\
\hline $\begin{array}{l}\text { Based on different } \\
\text { customs }\end{array}$ & $\mathrm{X}$ & & & & & & $\mathrm{X}$ & & & & $\mathrm{x}$ & 9 \\
\hline $\begin{array}{l}\text { Based on different } \\
\text { traditions }\end{array}$ & & & & & & & & & $X$ & & & 8 \\
\hline $\begin{array}{l}\text { Mixture of belief system } \\
\text { and values }\end{array}$ & $\mathrm{X}$ & $\mathrm{X}$ & $\mathrm{X}$ & & & $\mathrm{x}$ & $\mathrm{X}$ & $\mathrm{X}$ & $\mathrm{X}$ & $\mathrm{X}$ & $X$ & 20 \\
\hline $\begin{array}{l}\text { Mixture of norms and } \\
\text { standards }\end{array}$ & $\mathrm{X}$ & & & & & & & & & & & 8 \\
\hline Different lifestyle & $\mathrm{X}$ & & $\mathrm{X}$ & $\mathrm{X}$ & & $\mathrm{x}$ & $\mathrm{x}$ & $\mathrm{x}$ & & $\mathrm{x}$ & $\mathrm{x}$ & 18 \\
\hline
\end{tabular}

1. AMERICAN ACADEMY OF PEDIATRICS, 2000: Enhancing the racial and ethnic diversity of the pediatric workforce (RE9931). Pediatrics. 105(1): 129-131.

2. ANDREWS, MM \& BOYLE, JS 1999:

Transcultural concepts in nursing care. Lippincott, Philadelphia.

3. BOUWER, M; DREYER, M; HERSELMAN, $S$ \& HATTINGH, HS: Contemporary trends in community nursing.

4. BOWMAN, BT 1994: Cultural diversity and academic achievement. Ncrel urban education program, Chicago. http://www.ncrel.org/sdrs/areas/issues/ educatrs/leadrshp/le0bow.htm.
5. CARLOWE, J 1998: Orthodox care No thanks for the memories. Nursing Times. December 2, 94(48): 32-33.

6. CHIPFAKACHA, V 1994: The role of culture in primary health care. SAMJ. 84 (12) December 1994; 860-862.

7. CLARK, MJ 1996: Nursing in the community. Second edition. Appleton \& Lange, Connecticut.

\section{ETHNIC AFFAIRS COMMISSION} OF NSW 2001: Ethnic affairs and cultural diversity. Sydney. http:// www.eeo.nsw.gov.au/jobs/eeointro/ diversity.htm

9. FERGUSON, SA 1994: Facilitating multicultural competence. Child Care
Worker. 12 (7) July 1994: 3 \& 4

10. HAYES, VL 1998: Appreciating patient diversity. AJN. 98 (11) November 1998 p. 80.

11. IRVINE, JM 1994: Sexual cultures and the construction of adolescent identities. Temple University Press, Philadelphia. Pp. 3 - 25.

12. JARVIS, D 1998: Transcultural nursing. Seeing things in black and white. Nursing Times. 94 ( 42), October 1998. Pp. 32 \& 33.

13. JEZEWSKI, MA 1993: Culture brokering as a model for advocacy. Nursing \& Health Care. February 1993. Pp. 78-85. 
14. LEE, B 1999: Tackling racism. Nursing Standard. 12 (28), March 1999. Pp. 14-16.

15. LEININGER, M 1994: Transcultural nursing education: A worldwide imperative. Nursing \& Health Care. 15 (5) May 1994. Pp. 254-257.

16. MCCAFFERY, M 1999: Pain Control. AJN, 99(8): 18.

17. MELIFONWU, R 1999: Supporting Act. Nursing Standard. 13(40): 18.

18. MENSAH, J 1999: The richest mix. Nursing Standard. 13(23): 70.

19. ROSELLA, JD; REGANKUBINSKI, MJ \& ALBRECHT, SA 1994: The need for multicultural diversity among health professionals. Nursing \& Health Care. 15,(5): 242-246.

20. SADLER, C 1999: Promoting diversity Nursing Standard. 13(39): 1416.

21. SPRADLEY, BW \& ALLENDER, JA 1996: community health nursing concepts and practice. Fourth Edition. Lippincott, Philadelphia.

22. ENGBRETSON, J \& LITTLETON, LY2001: Cultural negotiation: A constructivist - based model for nursing practice. Nursing Outlook. September/ October 2001: 223-230.

23. GIGER, JN \& DAVIDHIZAR, R 2002: Culturally competent care: Emphasis on understanding the people of Afghanistan, Afghanistan Americans, and Islamic culture and religion. International Council of Nurses. International Nursing Review. 49(2): 7986. 


\section{INTERNATIONAL CLASSIFICATION FOR NURSING PRACTICE (ICNP)}

The term CULTURAL DIVERSITY is being considered for inclusion in the International Classification for Nursing Practice (ICNP).

\section{INSTRUCTIONS FOR FILLING IN THE FORM}

- The suggested characteristics of CULTURAL DIVERSITY as identified by the Gauteng Research Group are submitted for your perusal. Please indicate in the relevant space if you agree(yes) or disagree (no) with the characteristics selected as the essential characteristics of CULTURAL DIVERSITY

- $\quad$ Please use the extra space provided for comments that you wish to include. Remember that your recommendation and suggestions are important.

- $\quad$ Time needed for completion of the form will be an estimated 5 minutes.

- If you require any assistance regarding this form or more information on the ICNP, you can contact Ms. N Geyer (012) 3432315 or Ms. E Uys (012) 8074648.

\section{TICK IN THE RELEVANT SPACE IF YOU AGREE (YES) OR DISAGREE (NO) WITH THE SELECTED CHARACTERISTICS}

\begin{tabular}{|ll|l|l|l|}
\hline No $\quad$ Characteristics & Yes & No & Remarks \\
\hline 1. & Co-existence of ethnic groups & & & \\
\hline $2 . \quad$ Based on different customs & & & \\
\hline 3. & Based on different tradition & & & \\
\hline $4 . \quad$ Mixture of belief systems and values & & & \\
\hline $5 . \quad$ Mixture of norms and standards & & & \\
\hline 6. & Different life style & & & \\
\hline
\end{tabular}

Do you have any suggestions or comments?

- It would be appreciated if you could supply the following data should we require more assistance but this information is optional:

Name:

Nurse Practitioner: Yes ( ) No ( )

Current Workplace:

Other: (Specify)
Person responsible for collecting form:

Telephone:

Date of Collection:

THANK YOU FOR YOUR PARTICIPATION

69

Curationis May 2005 